\title{
TECNOLOGIAS DIGITAIS NA EDUCAÇÃO: EXPERIÊNCIA DO USO DE APLICATIVOS DE CELULAR NO ENSINO DA BIOLOGIA
}

\author{
RAQUEL PONTES DOS SANTOS \\ SILVIA REGINA SAMPAIO FREITAS
}

\section{RESUMO}

Este trabalho visou elaborar, aplicar, e comparar o rendimento e a opinião dos estudantes do segundo ano do Ensino Médio a partir de sequências didáticas ancoradas no método tradicional de ensino, com sequências didáticas complementadas com mídias digitais. O estudo foi realizado no segundo semestre de 2016, em uma escola da rede pública de ensino, localizada no município de Tefé-AM. Para a execução da sequência didática pautada no uso de métodos de ensino tradicional, utilizaram-se um quadro branco e um livro didático. Na sequência didática com mídias digitais, empregaram-se aplicativos educativos disponíveis para aparelhos de celular. A partir da comparação dos resultados dos questionários aplicados no final das duas metodologias de ensino, verificou-se que o emprego das sequências didáticas mediadas com tecnologia digital facilitou o processo de ensino e aprendizagem nas aulas de Biologia.

Palavras-chave: Mídias Digitais. Celular. Sequência Didática.

\begin{abstract}
This work aimed to elaborate, apply, and compare the performance and opinion of second year high school students about didactic sequences based on the traditional method of teaching, with didactic sequences complemented with digital media. The study was carried out in the second half of 2016 at a public school, located in the municipality of Tefé-AM. For the accomplishment of the didactic sequence ruled in the use of traditional teaching methods was used whiteboard and didactic book. To
\end{abstract}


implement the didactic sequence with digital media, educational applications were available for mobile devices. From the comparison of the results of the questionnaires applied at the end of the two teaching methodologies, it was verified that the use of didactic sequences mediated with digital technology, facilitated the teaching and learning process in Biology classes.

Key-words: Digital Media. Mobile Phone. Following Teaching.

\section{INTRODUÇÃO}

O desenvolvimento de ferramentas tecnológicas emerge em nossa sociedade como alternativa à comunicação e organização das atividades humanas (MACHADO; TIJIBOY, 2005). As mídias sociais, tão utilizadas e amplamente conhecidas, são a modernização de um fenômeno muito maior, no qual Maluf \& Souza (2008) afirmam que: "no ensino de Ciências e Biologia as mídias sociais podem incorporar novos elementos na estrutura conceitual dos educandos, desencadeando a aprendizagem". Sem dúvida, essa aprendizagem representa um dos maiores desafios da educação, conforme já citava Ribeiro em 2014: “O magistério que hoje se reclama tem de ser um campo aberto como ponto de encontro das mais variadas tendências e soluções".

[...] Uma das grandes inovações da Web 2.0 foi mudar esse paradigma, ao apresentar ferramentas mais interativas e fáceis de serem utilizadas, acabando com as barreiras que ainda sobravam entre as pessoas e entre a produção de conhecimento [...] (RIBEIRO, 2014).

As Mídias Digitais de Informação e Comunicação, como os softwares disponibilizados por meio de aplicativos no aparelho celular, são de fácil propagação entre os jovens (MENEGAIS et al., 2015). Em virtude desse novo espaço, tais ferramentas oferecem recursos para potencializar os processos de aprendizagem na área de educação abrindo novas possibilidades para complementar o ensino formal (COPABIANCO, 2010). Esses novos instrumentos inseridos no processo educacional podem 
ampliar a interatividade e a flexibilidade de tempo em sala de aula (SILVA-FILHA et al., 2016).

A vantagem em estender o espaço físico das salas de aula com os aplicativos é que muitos dos aplicativos disponibilizados para área de ensino não precisam estar conectados à internet. Por conseguinte, o aluno não é limitado com buscas na Web (RAMOS, 2012), o que facilita a utilização em locais que não possuem internet, como observado no município de Tefé-Amazonas. Nesse sentido, o uso do celular, que ocupou seu espaço permanente no cotidiano das pessoas, torna-se ferramenta atrativa e efetiva no ambiente educacional (MOTTA, 2012).

Considerando a utilização de tecnologias digitais para o desenvolvimento de conteúdos teóricos de forma eficiente, dinâmica e prazerosa, o presente estudo visou elaborar, aplicar, e comparar o sucesso de duas sequências didáticas, uma pautada no método tradicional de ensino e a segunda baseada no uso de tecnologias digitais, para a promoção da aprendizagem efetiva. Para tanto, a temática utilizada foi "Sistema Locomotor Humano".

\section{PROCEDIMENTO METODOLÓGICO}

Este trabalho foi realizado no segundo semestre de 2016, em uma escola pública situada no município de Tefé, interior do Amazonas. O método de seleção da escola foi o da conveniência, pois a escola envolvida neste estudo é uma instituição parceira da Universidade do Estado do Amazonas e, portanto, acolhe os acadêmicos dos cursos de licenciatura que desenvolvem projetos de ensino e pesquisa.

Participaram dessa pesquisa 37 alunos (14 meninas e 23 meninos) de duas turmas do segundo ano do ensino médio (EM). No período em que esse estudo foi executado, os alunos participantes tinham entre 14 e 19 anos de idade. Os critérios para a inclusão dos participantes no estudo foram: ser aluno do segundo ano do ensino médio, e ter interesse em participar das atividades pedagógicas propostas neste trabalho. Excluiu-se da pesquisa os alunos ausentes no dia da execução das atividades pedagógicas. Todas as atividades conduzidas na sala de aula foram acompanhadas pelo professor responsável da disciplina "Biologia". 


\section{Sequência Didática Baseada no Método \\ Tradicional de Ensino}

Essa sequência didática foi aplicada na turma 01 do segundo ano do ensino médio (EM-1). Para a execução dessa abordagem, utilizou-se como recurso pedagógico aulas expositivas e dialogadas, complementadas com o livro didático. Também se fez uso de equipamento de Datashow para a apresentação de exemplos ilustrados.

Essa sequência didática teve a duração de seis aulas consecutivas, com duração de 50 minutos cada. A Tabela 1 sumariza as atividades realizadas no decorrer da sequência didática.

Tabela 1: Detalhamento da sequência didática baseada no método tradicional de ensino.

\begin{tabular}{|c|c|c|}
\hline Assunto & Metodologia & Atividade Complementar \\
\hline $\begin{array}{l}\text { Características dos } \\
\text { Sistemas Locomotor e } \\
\text { Esquelético. }\end{array}$ & $\begin{array}{l}\text { Aula } \\
\text { Expositiva }\end{array}$ & $\begin{array}{l}\text { Identificação dos ossos atra- } \\
\text { vés de pinturas de figuras. }\end{array}$ \\
\hline $\begin{array}{l}\text { Sistema Esquelético: } \\
\text { classificação dos ossos. }\end{array}$ & $\begin{array}{l}\text { Aula } \\
\text { Expositiva }\end{array}$ & $\begin{array}{l}\text { Redação sobre os tipos de } \\
\text { ossos. }\end{array}$ \\
\hline Sistema Articular. & $\begin{array}{l}\text { Aula } \\
\text { Expositiva }\end{array}$ & $\begin{array}{l}\text { Identificação das articula- } \\
\text { ções através de pinturas de } \\
\text { figuras. }\end{array}$ \\
\hline $\begin{array}{l}\text { Sistema Articular e } \\
\text { Doenças Relacionadas. }\end{array}$ & $\begin{array}{l}\text { Aula } \\
\text { Expositiva }\end{array}$ & $\begin{array}{l}\text { Quebra-cabeças com as ima- } \\
\text { gens sobre sistema articular. }\end{array}$ \\
\hline Sistema Muscular. & $\begin{array}{l}\text { Aula } \\
\text { Expositiva }\end{array}$ & $\begin{array}{l}\text { Aplicação de atividades } \\
\text { sobre classificação dos } \\
\text { músculos. }\end{array}$ \\
\hline $\begin{array}{l}\text { Sistema Muscular e } \\
\text { Doenças relacionadas. }\end{array}$ & $\begin{array}{l}\text { Aula } \\
\text { Expositiva }\end{array}$ & ão Final. \\
\hline
\end{tabular}

\section{Sequência Didática Ancorada no Método de Ensino com Tecnologia Digital}

A sequência didática mediada com tecnologia digital foi aplicada na turma 02 do segundo ano do EM (EM-2). Essa sequência baseou-se no uso dos aplicativos de celular Bones 
3D Anatomy, 3D Bones and Organs e Muscles 3D como ferramentas de metodologias complementares ao ensino do Sistema Locomotor (Tabela 2). As aulas ocorreram de forma expositiva, dialogada e complementadas com o uso dos aplicativos. Os alunos, organizados em duplas, acompanhavam o conteúdo ministrado através dos aplicativos instalados nos celulares dos estudantes.

Tabela 2: Detalhamento da sequência didática com tecnologia digital.

\section{Assunto Metodologia Atividade Complementar}

Características dos Sis-

temas Locomotor e AE e "Bones 3D" Resolução de quiz no apliesquelético.

cativo

Sistema Esquelético: classificação dos ossos.

AE e "Bones 3D" Revisão oral da aula anterior

Sistema Articular.

AE e "3D Bones Resolução de quiz no apliand Organs" cativo

Sistema Articular e AE e "3D Bones

Doenças Relacionadas. and Organs"

Revisão oral da aula anterior

Sistema Muscular. AE e "Muscles 3D" $\begin{aligned} & \text { Resolução de quiz no apli- } \\ & \text { cativo }\end{aligned}$

Sistema Muscular e

Doenças relacionadas.

AE e "Muscles 3D" Avaliação Final.

Legenda: $\mathrm{AE}=$ aula expositiva

Aplicativo Bones 3D Anatomy (GALVAN, 2015): esse aplicativo fornece informações em três dimensões e é altamente detalhado, do esqueleto humano (Figura 1). O modelo esquelético apresentado no aplicativo pode ser manipulado de diferentes formas: 1) ao dar o zoom na estrutura óssea desejada é possível verificar as delimitações de suas extremidades, o que facilita a compreensão dos acidentes ósseos; 2) as informações do texto localizado na parte inferior ao modelo tridimensional 
estão disponíveis em português, podendo ser maximizadas ou minimizadas; e 3) ao selecionar qualquer osso, este muda de cor, facilitando a visualização de seus limites e suas formas. Adicionalmente, as informações anatômicas podem ser acessadas sem que o telefone celular esteja conectado à internet.

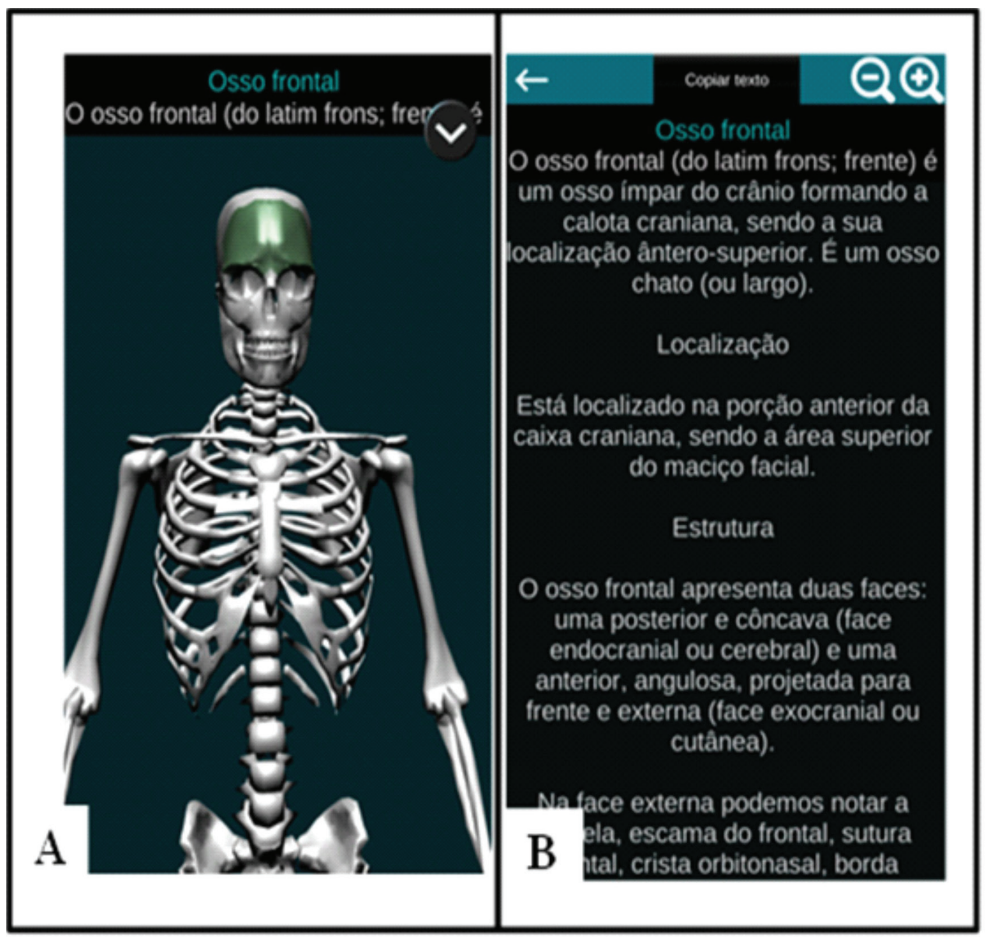

Figura 1: Captura das telas do aplicativo Bones 3D Anatomy mostrando a estrutura em três dimensões dos ossos. (A) Osso frontal destacado em verde escuro no esqueleto e acima texto adicional com informações sobre o osso em destaque. (B) Informações obtidas ao clicar na seta voltada para baixo acima do esqueleto sobre a localização e estrutura do osso em destaque.

Aplicativo 3D Bones and Organs (EDUCATION MOBILE, 2015): esse segundo aplicativo possui um conjunto de imagens em alta resolução, e em três dimensões, permitindo a visualização detalhada dos sistemas que compõem o corpo humano (Figura 2). 


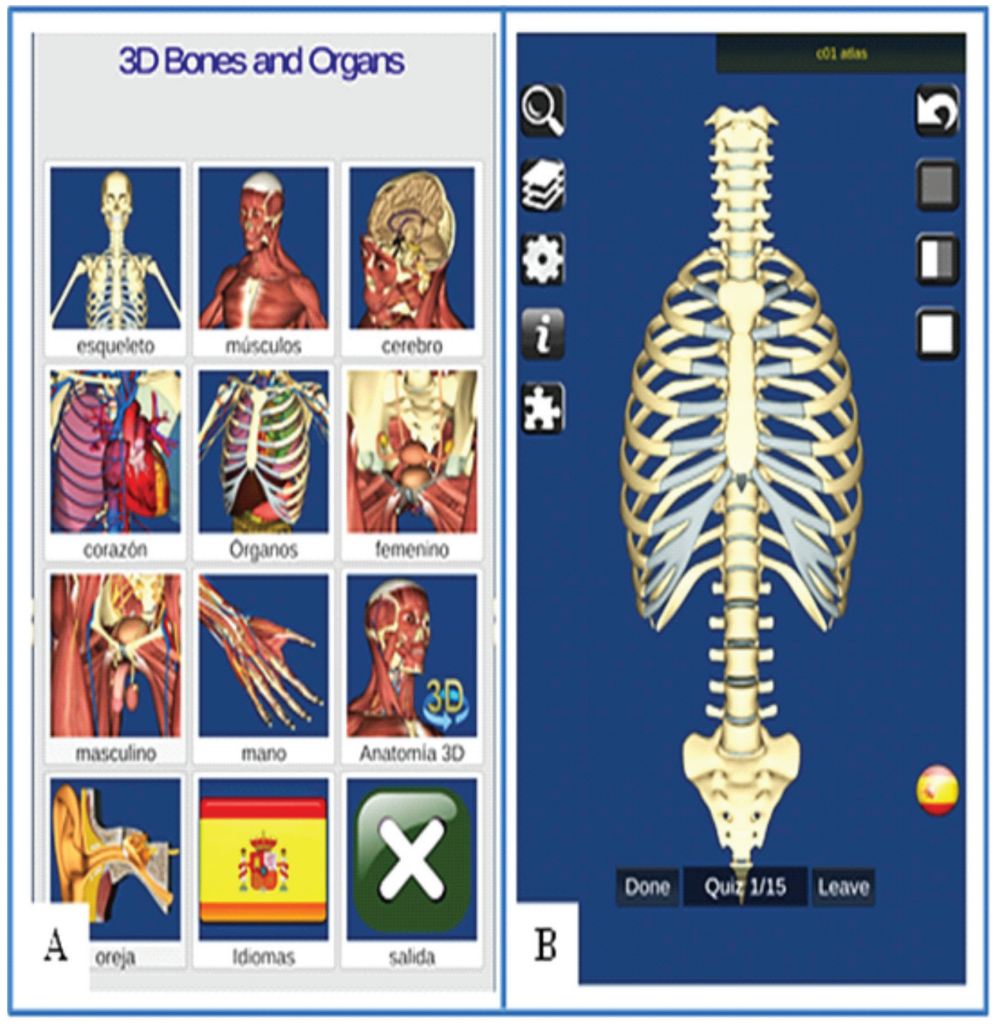

Figura 2: Captura das telas do aplicativo 3D Bones and Organs. (A) Tela inicial representando ícones dos sistemas do Corpo Humano disponíveis no aplicativo, ícone de idiomas disponíveis e os demais ícones com outros recursos do aplicativo. (B) Parte do esqueleto axial com ossos da coluna vertebral, costelas e pelve, demonstrando estruturas do sistema esquelético e articular em três dimensões.

Aplicativo Muscles 3D (GALVAN, 2016): esse aplicativo ilustra exclusivamente o sistema muscular (Figura 3). Os modelos musculares são apresentados em três dimensões, e contêm informações sobre todos os grupos musculares. 


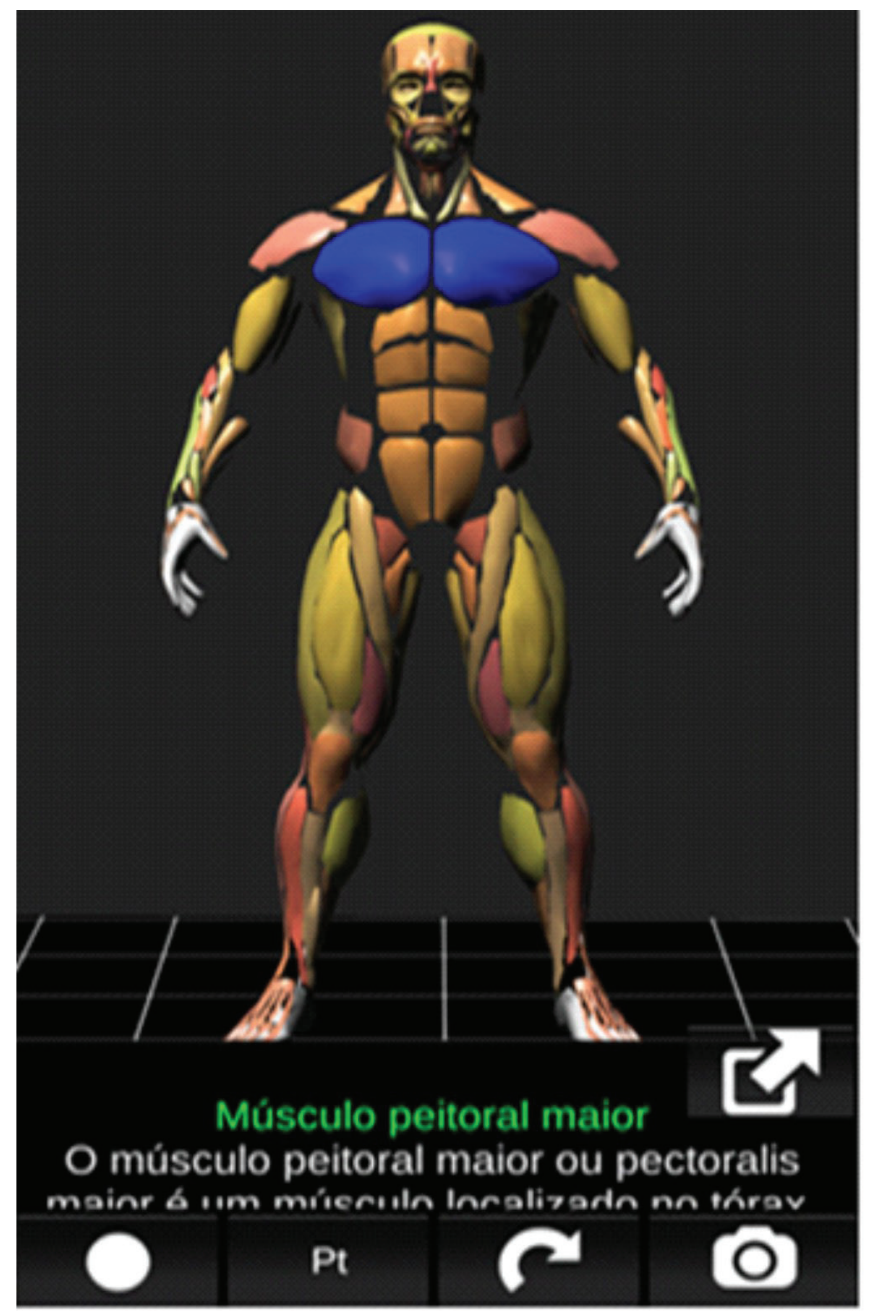

Figura 3: Captura da tela do aplicativo Muscles 3D representando os músculos em três dimensões com os músculos do peitoral em destaque na cor azul, com informações abaixo, que podem ser maximizadas ou não, sobre os músculos em destaque. 


\section{Avaliação E Validação das Metodologias de Ensino}

Ao final das sequências didáticas, os estudantes das turmas EM-1 e EM-2 foram convidados a responder um questionário padrão (Avaliação Final) que continha cinco questões discursivas sobre o tema "Sistema Locomotor". Utilizou-se esse instrumento para avaliar o desempenho da estratégia de ensino tradicional, ancorada em mídias digitais para a aquisição do conhecimento. As questões utilizadas no questionário incluíram: (1) classifique os ossos segundo tamanho e forma; (2) discuta as atribuições dos ossos no funcionamento do sistema locomotor; (3) discuta as atribuições dos músculos no funcionamento do sistema locomotor (4) informe os componentes do sistema locomotor; (5) qual a função do sistema locomotor? As respostas foram categorizadas em Resposta Correta e Resposta Incorreta. Para a análise qualitativa do questionário, utilizamos a Análise de Conteúdo, como proposto por Bardin (2011).

O questionário também continha duas questões para avaliar o grau de satisfação dos alunos quanto à metodologia de ensino utilizada. Para tanto, os alunos foram solicitados a informar: "Como você avalia a atividade?", e "A metodologia de ensino facilitou a aprendizagem?". Todos os resultados foram tabulados e apresentados em forma de gráfico.

\section{RESULTADOS E DISCUSSÃO}

\section{Método Tradicional de Ensino e o Método Baseado no Uso de Tecnologias Digitais}

No curso da sequência didática ancorada no método tradicional de ensino, os alunos apresentaram comportamento inquieto e desatento. Não foi observado interesse ou curiosidade pelo assunto ministrado. E, quando solicitados para responder ao questionário de avaliação final, verificou-se que os alunos ficaram mais preocupados em copiar dos colegas do que discutir as funcionalidades do sistema locomotor. Logo, concluímos que essa metodologia de ensino não foi capaz de despertar a curiosidade dos alunos sobre o assunto, ou promover o conhecimento efetivo. 
Em contraste, a utilização das tecnologias digitais - os aplicativos para celular - teve excelente receptividade por parte dos estudantes. Os alunos, desde o início, mostraram-se interessados, curiosos e entusiasmados com o desenvolvimento da atividade, principalmente ao terem conhecimento de que iriam utilizar o celular para visualizar e interagir com os componentes do sistema locomotor. O uso dessa abordagem despertou a curiosidade sobre as peculiaridades e funcionalidades dos ossos e músculos, e como esses órgãos trabalham integrados para que o organismo possa executar tipos variados de movimentos.

$\mathrm{Na}$ abordagem de temas complexos, como no caso do tema sistema locomotor, é fundamental a inclusão de metodologias que complementem e instiguem competências e habilidades dos estudantes (SILVA et al., 2016; SILVA-FILHA et al., 2016). Nesse contexto, a estratégia de integrar tecnologias digitais com aulas expositivas mostrou-se válida por despertar a curiosidade e estimular o interesse dos estudantes pelo assunto. Outra importante vantagem dessa estratégia foi sua capacidade de motivar os alunos a participar espontaneamente da aula (ALMEIDA et al., 2015). Acrescenta-se a isso o auxílio do caráter lúdico no desenvolvimento da cooperação, da socialização e das relações afetivas preconizadas para uma aprendizagem efetiva (OVIGLI, 2009).

\section{Avaliação do Conhecimento Adquirido}

Os resultados da avaliação final das turmas EM-1 e EM-2 estão sumarizados no Gráfico 1. 
Qual a função do sistema locomotor?
Informe os componentes do sistema locomotor.

Discuta as atribuições dos músculos no funcionamento do sistema locomotor.

Discuta as atribuições dos ossos no funcionamento do sistema locomotor.

Classifique os ossos segundo o tamanho e forma.

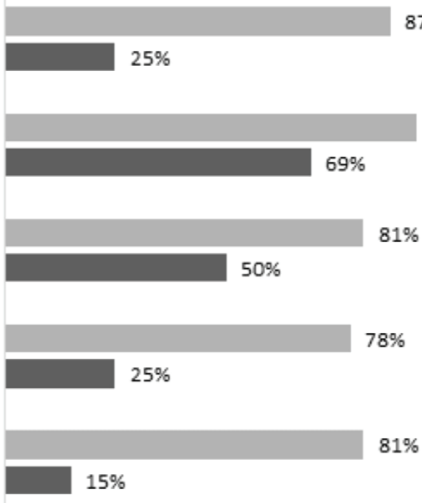

$\%$ das respostas corretas
$81 \%$

$8 \%$

$81 \%$

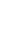

(n)


inserção de mídias digitais como um mecanismo básico para a educação, a exemplo dos aplicativos de celular no ambiente escolar, serve como suporte ao processo de ensino aprendizagem, incentivo para que esse tipo de experiência possa ocorrer muito mais nas formas e maneiras de ensinar; nas metodologias e estratégias que o professor utilizar em sua mediação ao ensino, potencializando assim ao máximo as possibilidades de aprendizagem construtivista (ALMEIDA et al., 2015).

\section{Percepção dos Alunos Sobre os Métodos de Ensino}

As duas últimas perguntas do questionário de avaliação final serviram para dimensionar a opinião dos alunos sobre os métodos de ensino utilizados neste estudo. Os resultados foram organizados nos Gráficos 2 e 3.

Quando questionados “como você avalia a atividade?”, 15\% da turma EM-1 indicou ser "boa", enquanto que 85\% consideraram "razoável” (Gráfico 2). Em contraste a esses achados, 53\% dos alunos da turma EM-2 consideraram a sequência didática "excelente" e 47\% afirmaram ser "boa".

O índice de satisfação dos alunos da turma EM-2, em contraste ao observado na turma EM-1, indicou que a inclusão de tecnologias digitais foi capaz de despertar curiosidade e o interesse dos alunos pelo assunto. Segundo Pereira e colaboradores (2012), o uso de dispositivos móveis pode servir para motivar os alunos e tornar o processo de aprendizagem com mais qualidade e com uma nova didática.

Para a questão "a metodologia de ensino facilitou a aprendizagem?", 5\% dos alunos da turma EM-1 afirmaram "sim”, contra 95\% da turma EM-2 (Gráfico 3). Esses resultados são semelhantes aos encontrados por Sant'anna e colaboradores (2011), que verificaram a opinião de discentes ao realizarem um jogo didático de tabuleiro. Constataram que 83\% dos participantes acreditam ser importante o uso de jogos em sala de aula. Cerca de $85 \%$ dos alunos responderam que, devido ao jogo ser dinâmico, isso facilitou a aprendizagem do conteúdo, bem como, $87 \%$ dos estudantes afirmaram que o jogo auxiliou na aprendizagem de conceitos não conhecidos. Um estudo 
qualitativo similar, feito por Almeida e colaboradores (2015), também evidenciou que os alunos do ensino médio superaram as dificuldades de compreensão dos conceitos do corpo humano após o uso de tecnologias digitais.

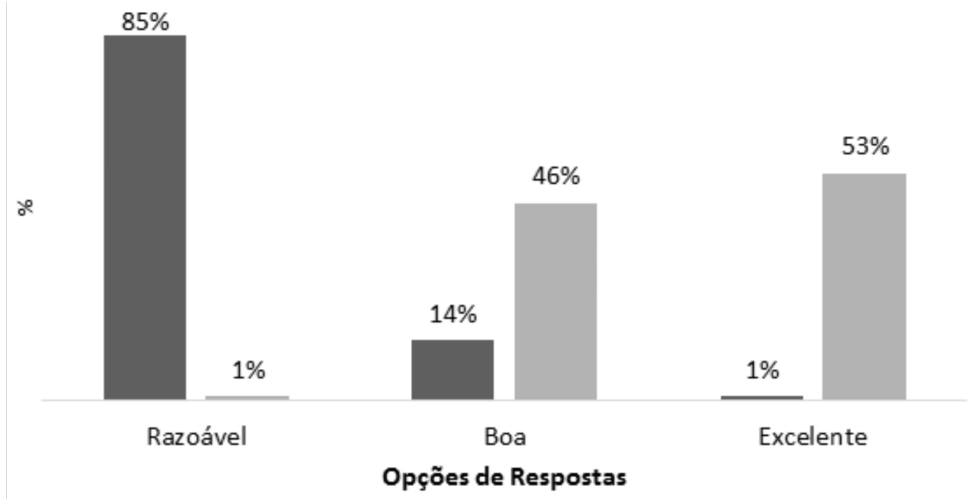

Gráfico 2: Percentual das respostas obtidas na avaliação final. A pergunta respondida pelos alunos: "Como você avalia a atividade?”. A turma EM-1 está representada pelas barras escuras, e a turma EM-2 está apresentada pelas barras claras.

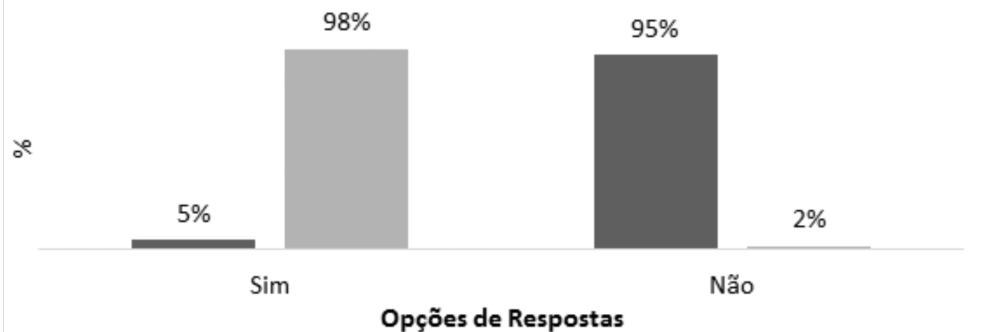

Gráfico 3: Percentual das respostas obtidas na avaliação final. A pergunta respondida pelos alunos: "a metodologia de ensino facilitou a aprendizagem?”. A turma EM-1 está representada pelas barras escuras, e a turma EM-2 está apresentada pelas barras claras.

Os dispositivos móveis, como os aparelhos de celular, associados a diferentes aplicativos, vêm proporcionando muitas mudanças na forma dos professores e alunos se relacionarem 
com a informação a produzir conhecimento, apresentando significativo potencial para transformar a maneira de ensinar e de aprender. Ainda, estima-se que os alunos possam interagir com outros estudantes, enriquecendo seus conhecimentos sobre as ciências, revendo e conhecendo conceitos trabalhados em sala de aula, e novos recursos didáticos (CRUZ; NERI, 2013; ALMEIDA et al., 2015).

\section{CONSIDERAÇÕES FINAIS}

Este estudo testou e validou o uso de tecnologias digitais - aplicativos educativos para telefone celular - para o ensino do sistema locomotor. A partir dos resultados obtidos no presente estudo, percebemos que inserir tecnologias digitais nas aulas de Biologia auxilia a viabilizar uma forma mais atrativa de ensinar os conteúdos, pois os alunos são receptivos a esse tipo de prática.

\section{REFERÊNCIAS}

ALMEIDA, C. M. M.; LOPES, L. A.; LOPES, P. T. C. Sequências didáticas eletrônicas no ensino do corpo humano: comparando o rendimento do ensino tradicional com o ensino utilizando ferramentas tecnológicas. Acta Scientiae, v. 17, n. 2, p. 466-482, 2015.

BARDIN, L. Análise de conteúdo. São Paulo: Edições 70, 2011, 80p.

CAPOBIANCO, L. Comunicação e Literacia Digital na Internet: estudo etnográfico e análise exploratória de dados do Programa de Inclusão Digital Acessa SP - PONLINE. Dissertação (Mestrado em Ciências da Comunicação). Escola de Comunicação e Artes, Universidade de São Paulo. São Paulo-SP, 2010 .

CRUZ, A. G.; NERI, D. F. M. A inserção de tablets em escolas da rede pública estadual na cidade de Petrolina-PE: uma percepção dos educadores e educandos. Revista de Educação do Vale do São Francisco, v. 4, n. 6, p. 6-26, 2013.

EDUCATION MOBILE. [Internet]. 3D Bones and Organs, versão 2015. [Acesso em 2016]. Disponível em: <https://www.microsoft.com/pt-br/ store/p/3d-bones-and-organs-anatomy/9wzdncrd91mw $>$.

GALVAN, V. M. G. [Internet]. Bones 3D Anatomy, versão 2015. [Acesso em 2016]. Disponível em: <https://www.microsoft.com/pt-br/store/p/organs-3d-anatomy/9nblggh07sp2>.

GALVAN, V. M. G. [Internet]. Muscle 3D, versão 2016. [Acesso em 2016]. Disponível em: <https://www.microsoft.com/pt-br/store/p/muscular-system-3d-anatomy/9nblggh07sh3>.

MACHADO, J. M. R.; TIJIBOY, A. V. Redes Sociais Virtuais: um espaço para 
efetivação da aprendizagem cooperativa. Novas Tecnologias na Educação, v. 3, n. 1, p. 1-9, 2005.

MALUF, M. C. G.; SOUZA, Q. A. R. A ficção científica e o ensino de ciências: o imaginário como formador do real e do racional. Ciência \& Educação, v. 14, n. 2, p. 271-282, 2008.

MARTINHO, T.; POMBO, L. Potencialidades das TIC no ensino das Ciências Naturais: um estudo de caso. Electrónica de Enseñanza de las Ciencias, v. 8, n. 2, p. 527-538, 2009.

MENEGAIS, D. A. F. N.; FAGUNDES, L. C.; SAUER, L. Z. A análise do impacto da integração da plataforma KHAN ACADEMY na prática docente de professores de matemática. Novas Tecnologias na Educação, v. 13, n. 1, p. 1-11, 2015.

MOTTA, E. M. Tablets na sala de aula: um desafio para professores e alunos; uma prática pedagógica consciente. Trabalho de Conclusão de Curso (Especialização). Universidade Cândido Mendes. Rio de Janeiro-RJ, 2012.

OVIGLI, D. F. B.; BERTUCCI, M. C. S. A formação para o ensino de ciências naturais nos currículos de pedagogia das instituições públicas de ensino superior paulistas. Ciências \& Cognição, v. 14, n. 2, p. 194-209, 2009.

PEREIRA, T. A.; TARCIA, R. M. L.; SIGULEM, D. Tecnologias móveis: aliadas na educação e na saúde. IN: XIII Congresso Brasileiro em Informática em Saúde. Curitiba. 2012.

RAMOS, M. R. V. O uso de tecnologias em sala de aula. LENPES - PIBID de ciências sociais, 2. ed., n. 2, v. 1, p. 16, 2012.

RIBEIRO, C. G. B. Organização e produção de conhecimento acadêmico-científico no Facebook. Trabalho de Conclusão de Curso. Escola de Biblioteconomia, Universidade Federal do Estado do Rio de Janeiro. Rio de Janeiro-RJ, 2014.

SANT'ANNA, I. C.; BRANCO, A. L. C.; PEREIRA, K. P.; CARVALHO, A. C. P.; TAVARES, M. G. Perfil da Genética: Uma maneira divertida de memorizar conteúdos. Genética na Escola, v. 6, n. 2, p. 17-29, 2011.

SILVA, A. A.; SILVA-FILHA, R. T.; FREITAS, S. R. S. Utilização de modelo didático como metodologia complementar ao ensino da anatomia celular. Biota Amazônia, v. 6, n. 3, p. 17-21, 2016.

SILVA-FILHA, R. T.; SILVA, A. A.; FREITAS, S. R. S. Uma alternativa didática às aulas tradicionais de ciências: aprendizagem colaborativa e modelização aplicadas ao ensino do sistema urinário. Cadernos de Educação, v. 15, n. 31, p. 87-105, 2016.

\section{SOBRE AS AUTORAS}

Raquel Pontes dos Santos é acadêmica do Curso de Licenciatura em Ciências Biológicas. Centro de Estudos Superiores de Tefé. Universidade do Estado do Amazonas. raqueldossantos-2@hotmail.com

Silvia Regina Sampaio Freitas é professora adjunta do Curso de Licenciatura 
em Ciências Biológicas. Centro de Estudos Superiores de Tefé. Universidade do Estado do Amazonas (CEST-UEA). Coordenadora do Subprojeto do Programa Institucional de Bolsa de Iniciação à Docência e do curso de Licenciatura em Ciências Biológicas - Oferta Especial. Possui Mestrado e Doutorado em Genética Humana pelo Instituto Oswaldo Cruz - FIOCRUZ e Pós-Doutorado pela Faculdade de Medicina da USP.silvia.sampaio.freitas@hotmail.com 